\title{
LAS MODALIDADES DE EROTIZACIÓN DE LAS FIGURAS POLÍTICAS EN LOS MEDIOS DE PRENSA SENSACIONALISTAS CHILENOS ${ }^{1}$
}

\author{
Mariana Valenzuela Somogyi ${ }^{2}$
}

\section{Resumen/Abstract}

El artículo desarrolla la noción de modalidades de erotización, como la reelaboración simbólica del deseo sexual, para analizar la representación de las figuras de mujeres y hombres en la política chilena por parte de dos medios escritos de prensa sensacionalista, Las Últimas Noticias y La Cuarta. Se identifican dos formas de representación principales: 1) la construcción de un imaginario sobre el atractivo sexual de las figuras políticas, transformándoles en objetos de deseo, y, 2) la significación de la seducción y la capacidad de conquista como una táctica de poder. Bajo la perspectiva de que los medios de comunicación responden de manera más rápida que las instituciones a las transformaciones sociales, propone que estas representaciones responden a un contexto de personalización de la política, buscando ser una contribución para una mayor apertura analítica del área de estudios de género y política desde la óptica en la sexualidad.

Palabras clave: modalidades de erotización, mujeres y hombres en política, Chile, medios de prensa sensacionalista

\footnotetext{
${ }^{1}$ El artículo se basa en los principales hallazgos y conclusiones de mi tesis para optar al grado de Magíster en Ciencias Sociales. Ver: Valenzuela, M. (2012). Las modalidades de erotización de la imagen de mujeres y hombres en la política chilena en la prensa escrita sensacionalista: El caso de Las Últimas Noticias y La Cuarta (tesis de magíster). Universidad Academia de Humanismo Cristiano, Santiago.

${ }^{2}$ Chilena, Universidad de Santiago. E-mail: marianav83@gmail.com
} 


\section{THE MODALITIES OF EROTIZATION OF THE POLITICAL FIGURES IN THE CHILEAN SENSATIONALIST MEDIA}

The article develops the notion of eroticization modalities, as the symbolic re-elaboration of sexual desire, to analyse the representation of the figures of women and men in Chilean politics by two written sensational media, Las Últimas Noticias and La Cuarta. Two main forms of representation is identified: 1) the construction of an imaginary about the sexual attractiveness of political figures, transforming them into objects of desire, and 2) the significance of seduction and the capacity for conquest as a tactic of power. From the perspective that the media respond more quickly than institutions to social transformations, it proposes that these representations respond to a context of personalization of politics, seeking to be a contribution to a larger analytical opening of the area of gender studies and politics from the outlook on sexuality.

Keywords. modalities of erotization, women and men in politics, Chile, sensational media.

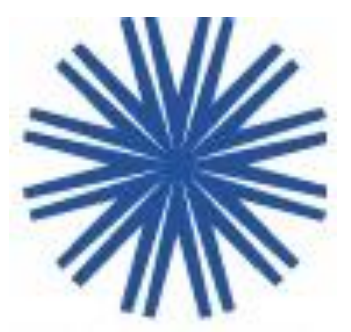

Introducción

Desde la década de los noventa en América Latina ha habido un incremento del número de mujeres en puestos importantes de decisión en las esferas que componen los poderes ejecutivo y legislativo del sistema político. Sigue habiendo una sub representación femenina, es un reflejo de su traspaso de los límites establecidos tradicionalmente por la distinción entre las esferas pública y privada, implicando una transformación en los modos en los que se representa su figura y su concepción como sujetos con legitimidad en el plano de la política. 
Se pueden dividir los estudios sobre género y política que abordan las formas de representación de la figura de las mujeres en la esfera política en dos líneas. La primera, predominante en América Latina, señala que ellas han sido tradicionalmente caracterizadas mediante la imagen de la madre (Chaney, 1983; Montecino, 1996), identificándolas como símbolos de la virtud y la moral (Sreberny y van Zoonen, 2000). La segunda, preponderante en Norteamérica y Europa, argumenta que son representadas como objetos sexuales, sometidas a relaciones de dependencia y sumisión por sus pares masculinos en política y su electorado (Freedman, 1997; Ross, 2004). Esta última línea de análisis se fundamenta en una concepción de poder que tiene sus raíces en el concepto de sexualidad que ha sido desarrollado por la teoría feminista radical. En ella, la sexualidad es concebida como una forma de dominación impuesta por los hombres hacia las mujeres como grupo social, siendo la base para la construcción de un sistema patriarcal que rige la sociedad (Millet, 1995). Siguiendo esta concepción, los estudios de la segunda línea mencionada argumentan que, particularmente en los medios de comunicación, las mujeres en política son deslegitimadas ante las figuras masculinas mediante una representación negativa de su sexualidad. Estudios desde una perspectiva de género que abarquen la representación de la figura de hombres en política son escasos y tienden a señalar 
que se los representa desde una noción de masculinidad hegemónica (Wahl-Jorgensen, 2000; Achin y Dorlin, 2008).

Araujo (2010) plantea en un análisis que desarrolla sobre las formas de representación en medios de prensa escrita de la figura de la primera presidenta de Chile, Michelle Bachelet, que sobre su imagen se profieren dos tipos de representaciones, la figura de la madre y la del cuerpo y del erotismo como locus de control. De acuerdo a la segunda, habría un simbolismo que se genera sobre la imagen de Bachelet, y su relación con hombres en la política institucional, que la representa primordialmente en clave erótica, reflejando la imagen de mujeres y hombres en la esfera política institucional como cuerpos sexuados. Ello permite inquirir en la existencia de modalidades de erotización como una forma de representación de la figura de mujeres y de hombres en política. La acción de erotizar a la que alude forma parte integrante de la concepción de sexualidad mediante el erotismo, pensándolo como un concepto que implica la relación con un otro marcado por el juego y la performance de la seducción. En este sentido cabe preguntarse si el erotismo permitiría reflexionar las representaciones que se hacen sobre la figura de mujeres y hombres en política institucional desde un ángulo analítico diferente del plano unidimensional que se le ha otorgado a la sexualidad como expresión de formas de dominación. 
Se expandirá el análisis de las modalidades de erotización más allá de la figura de Bachelet para preguntarse sobre la representación que se realiza desde ella sobre las figuras de mujeres y hombres que ejercen o aspiran a ejercer puestos de representación en el poder ejecutivo y legislativo. Para realizar este tipo de análisis aparecen como elemento ideal los medios de comunicación de masas sensacionalistas, debido a que son industrias culturales con una lógica de mercado (Macé, 2006) que buscan generar un nivel de identificación con sus lectores, desarrollando un lenguaje y una forma particular de describir la realidad nacional que los diferencian de otros medios de comunicación representados como de carácter más serio y formal (Sunkel, 1985 y 2001). En Chile los principales medios de prensa escrita de ese tipo son Las Últimas Noticias (LUN) y La Cuarta ${ }^{3}$. Este artículo se enfoca en la representación de las figuras de mujeres y hombres en política institucional en ambos medios desde la perspectiva de las modalidades de erotización, durante los años 2008 y $2009^{4}$. Este

${ }^{3}$ La Cuarta y Las Últimas Noticias tienen grandes índices de lectoría y circulación a nivel nacional. Según el boletín de circulación y lectoría de diarios correspondiente al primer semestre del año 2009, La Cuarta se ubicaba en el segundo lugar en tiraje semanal con 141.084 ejemplares, y las Últimas Noticias en el tercero con 134.630 ejemplares distribuidos. En términos de lectoría semanal, La Cuarta se ubicaba en el primer lugar con 559.007 lectores, seguido por Las Últimas Noticias con 377.733 lectores.

${ }^{4}$ En la época existían dos grandes coaliciones políticas en el país. La Concertación de Partidos Por la Democracia que agrupaba a partidos de centro y de izquierda, era la coalición gobernante durante el período analizado. Lo integraban el Partido Demócrata Cristiano (DC), el Partido Por la Democracia (PPD), el Partido Socialista (PS) y el Partido Radical Social Demócrata (PRSD). La Alianza por Chile agrupa a los partidos de 
período está marcado en el país por ser la segunda mitad del gobierno de Michelle Bachelet y por las elecciones municipales y parlamentarias, viéndose incrementada la exposición de las figuras de mujeres y hombres en la política institucional durante las campañas electorales. Para ello, se efectuó una revisión de todos los ejemplares de ambos periódicos publicados en el período de tiempo señalado, seleccionando las notas que se referían a ellos, siguiendo la metodología del análisis de contenido cualitativo. Ésta comprende un conjunto de técnicas para elaborar, registrar y tratar datos más allá del ámbito social y cognitivo concreto en el que suele ocurrir la comunicación para lograr la emergencia del sentido profundo que procede de las prácticas sociales y cognitivas que produjeron el texto que es objeto de análisis (Piñuel, 2002; Ruiz, 2003).

El análisis propuesto encuentra su justificación en la proposición de las modalidades de erotización como una herramienta para el análisis de la construcción de las figuras femeninas y masculinas que actúan en la política institucional. Asimismo, pretende identificar cómo los medios de comunicación sensacionalistas chilenos utilizan las modalidades de erotización para interpretar el escenario de la política institucional, siendo una contribución para los (UDI). 
estudios de estos medios y el área de estudios de género y política.

Un abordaje teórico para las modalidades de erotización desde la noción de erotismo

El erotismo se elabora desde la primacía deseo sexual que lo distingue de otros campos de la sexualidad como lo son, por ejemplo, la reproducción o las relaciones de parentesco. Ello permite constituirlo como un ámbito de estudio aparte dentro del terreno de análisis de las sexualidades. Su vinculación al deseo sexual, desde la reflexión de Bataille (2002), lo caracteriza como un elemento fundamental que distingue a los seres humanos de los animales:

La actividad sexual reproductiva la tienen en común los animales sexuados y los hombres, pero al parecer sólo los hombres han hecho de su actividad sexual una actividad erótica, donde la diferencia que separa al erotismo de la actividad sexual simple es una búsqueda psicológica independiente del fin natural dado a la reproducción y del cuidado que dar a los hijos (p.15).

Para Bataille el erotismo es un aspecto de la vida interior del hombre que estaría animado por una búsqueda de continuidad. Ella es colocada por el autor en relación con la conciencia de la muerte desde la cual se instala al erotismo como una forma de romper con la discontinuidad suponiéndolo como un significante de la transgresión que se genera de la experiencia 
interior de los individuos, y que extrae su goce de la prohibición misma (Araujo, 1999). De acuerdo a Puleo (1992), el autor elaboró una teoría sistemática sobre el erotismo, aunque desde una base no científica, que lo comprende como la extensión de las connotaciones sexuales a seres y ámbitos que originalmente no estaban tocados por ella, siendo una relaboración simbólica. Pensar el erotismo significa hacerlo desde el ámbito de las representaciones que se han producido sobre él, y que han presentado diversas transformaciones y modalidades en el tiempo. Se le caracteriza fundamentalmente por ser un elemento transgresor fundado sobre el deseo que gobierna la vida interna de los seres humanos.

El erotismo ha sido un tópico frecuentemente tratado en la literatura, lo que ha derivado en que se establezca como un importante campo de investigación en el análisis literario. Schatzman (2003) establece que al erotismo se le atribuyen elementos del amor y la sensualidad que van acorde a la definición de la Real Academia Española de la noción en tanto 'amor sensual'. El autor señala que el concepto de erotismo que se expresa en la literatura se vincula estrechamente con la conceptualización elaborada por Bataille en tanto el erotismo se comprende como un elemento trasgresor que nos pone en distinción de una sexualidad propia de los animales. A partir de diversos estudios sobre erotismo en la obra literaria se puede observar que éstos parten de la noción de que "si la 
sexualidad humana evoca un acto biológico, el erotismo desvía el impulso sexual y lo transforma en representación" (Rosado, 2004, p. 24). Así, el erotismo se estructura siempre en torno a una potente carga simbólica sobre el deseo sexual.

El concepto de erotismo se define también en su oposición a la noción de pornografía. Locey (2002) plantea que, a diferencia de la pornografía, el erotismo se encuentra anclado en un contexto social o amoroso, mientras que la otra se estructura en torno a una simple descripción de los placeres sexuales fuera del ámbito de una relación interpersonal. Sobre éste tópico, Bozon (2005) señala que hacia mediados del siglo XX se cristaliza la distinción entre ambos como géneros literarios. El erotismo es concebido como de buen gusto en tanto evoca el deseo y el amor a diferencia de la pornografía que se caracteriza por presentar al acto sexual como un fin en sí mismo (Rosado, 2004). Se le destaca por ser un acto que permite la contemplación fetichista en la que el sexo en sí mismo deviene objeto de deseo, mientras que el erotismo es puesto en relación con la representación del ritual de la seducción y la contemplación del objeto de deseo, ubicándose en un contexto de mayor amplitud (González, 2007).

El erotismo implica la producción de un imaginario simbólico en el cual se inserta la representación de una relación marcada por la seducción y la interacción con un otro. De esta manera, se puede argumentar que la noción de erotismo se elabora 
sobre dos oposiciones principales. La primera, a partir de Bataille, se focaliza en la distinción entre una sexualidad animal y una sexualidad propiamente humana, que se caracteriza porque la reproducción no opera como un acto maquinal e instintivo. La segunda, desde los estudios literarios y filosóficos, realiza una distinción entre pornografía y erotismo, en la que el último adquiere parte relevante de su significado al operar desde la concepción de amor sensual, recalcando la importancia de la representación simbólica.

El concepto de modalidades de erotización en el que se fundamenta el análisis se comprende como la reelaboración simbólica del deseo sexual que extiende connotaciones de este tipo a entes y/o ámbitos que originalmente no poseían estas características, constituyéndose como un ritual de seducción basado en la representación del anhelo sexual por el cuerpo de un otro. En el análisis se utilizará el concepto de modalidades de erotización y no de erotismo pues el segundo si bien se distingue de la pornografía y la obscenidad, continúa teniendo un carácter muy explícito, aludiendo el primero de mejor manera a la acción de erotizar. Asimismo, se hace referencia a la idea de modalidades, y no de modalidad, para otorgar una apertura analítica a las diversas formas y significaciones que puede tener el acto de erotizar.

En base a esta concepción el análisis arrojó dos principales modalidades de erotización de la figura de mujeres y hombres 
en política en los periódicos sensacionalistas LUN y La Cuarta. La primera aborda la construcción del imaginario sobre el atractivo sexual de las figuras políticas, que van desde el cuerpo y la belleza de las mujeres a la galantería de los hombres, por ejemplo, transformándoles en objetos de deseo. La segunda se refiere a la seducción y la capacidad de conquista, como una táctica de poder con la que se representa a las figuras políticas. En cada modalidad de erotización se hará referencia primero a la representación que se hace sobre las mujeres en política y, en segundo lugar, a la representación que se hace sobre los hombres en política con el propósito de mostrar las diferencias entre ambos y desarrollar una comparación.

La construcción de los atributos asociados al atractivo sexual de mujeres y hombres en política.

En el caso de la representación de la figura de las mujeres que ejercen o aspiran a ejercer cargos en el poder ejecutivo y legislativo los medios de prensa sensacionalista analizados elaboran un imaginario sobre el cuerpo y la belleza femenina. Ello se sostiene primeramente en la descripción continúa de la vestimenta usada por ellas, constituyéndola como una parte integral de la historia que es relatada: "Son más que amiguis Michelle Bachelet ${ }^{5}$ y Cristina Fernández ${ }^{6}$. Son compinches presidenciables. La chilena rubia, vestida de un intenso rojo y

\footnotetext{
${ }^{5}$ Presidenta de Chile durante el período 2006-2010.

${ }^{6}$ Presidenta de Argentina durante el período 2007-2015.
} 
falda negra. La Argentina morena, ataviada en un lila pastel" (LUN, 5 de diciembre 2008, p.24).

La descripción de la vestimenta es un elemento base para la construcción del campo visual en el que las mujeres políticas se movilizan. La representación que se hace de ellas mediante ésta se efectúa bajo los códigos de estructuración de los periódicos sensacionalistas, siendo similar a la forma en la que se comenta el vestir de las personalidades ligadas al ámbito del entretenimiento. Ello tiene el propósito de incitar la participación del público lector mediante su opinión sobre un tema que identifican como parte de su conocimiento (Sunkel, 1985 y 2001). Se establece por medio este mecanismo una distinción con las figuras masculinas, que a su vez son relacionadas a los liderazgos políticos tradicionales. La descripción de la vestimenta de las mujeres en política tiene el propósito de demarcar en un primer momento la diferencia ligada directamente a la noción de femineidad que se está construyendo.

El detalle sobre la vestimenta da paso a la descripción sobre las características físicas de las mujeres en política, cumpliendo un último rol: las busca transformar en sujetos de contemplación. Ello puede verse en la imagen $\mathrm{n}^{\circ} 1$ con el caso de Ximena Rincón ${ }^{7}$ y la referencia que hace LUN a las medias

${ }^{7}$ Militante de la DC, candidata a senadora en las elecciones parlamentarias de 2009. 
caladas que usó en el discurso presidencial del 21 de mayo en el Congreso:

Imagen $n^{\circ} 1$.

LUN, 22 de mayo de 2008, p. 2

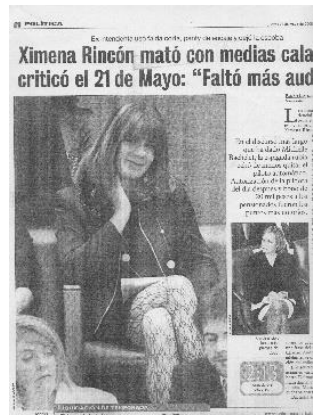

Ximena Rincón mató con medias caladas y criticó el 21 de mayo... Ex intendenta usó falda corta, panty de encaje y dejó la escoba. Los asistentes al mensaje presidencial que se ubicaron en la tribuna junto al Senado tuvieron una vista privilegiada de las piernas de Ximena Rincón, una de las postales inolvidables de un 21 de mayo lluvioso. Si en el 2006 fue la diputada DC Carolina Goic ${ }^{8}$ la que encandiló al público con sus piernas a lo Sharon Stone, ayer la osadía corrió por cuenta de la ex intendenta de Santiago, quien echó de menos que la audacia no estuviera tan presente en los anuncios de gobierno. (LUN, 22 de mayo de 2008, p. 2).

Las piernas de Rincón son retratadas como seductoras, siendo un elemento que ella resaltaría mediante el uso de una prenda

${ }^{8}$ Militante de la DC, candidata a reelección como diputada en las elecciones parlamentarias de 2009. 
identificada como provocativa. Incluso se hace un juego con este sentido, destacando su elección de vestimenta como una audacia, característica cuya falta ella misma criticaría del discurso presidencial. Se la compara con las piernas de la diputada Goic que llamó la atención por su atuendo dos años atrás, que aparece a modo de comparación en la figura $\mathrm{n}^{\circ} 1$, cuyo propósito era el mismo: atraer las miradas mediante el uso de su cuerpo y tipo de vestuario. Las medias utilizadas por Rincón y sus piernas fueron continuamente mencionadas en observaciones

como "ya no son las medias caladas el arma de seducción de Ximena Rincón. Ayer mató en el centro de eventos ANSCO con unos ajustados pantalones blancos y una polera de encajes de igual tono" (LUN, 6 de abril de 2009, p.12). Estas menciones se constituyen como elementos que son parte de la representación de sí como una figura política, sosteniéndose sobre la base de que se trata de la representación de un cuerpo sexuado y que a su vez está en concordancia con los cánones estéticos de belleza femenina. La descripción de la vestimenta de Rincón devela la construcción de un cuerpo que "mata”, es decir, un cuerpo atractivo que caracteriza y la hace resaltar por sobre las demás figuras políticas. 
Similar es lo que ocurre con la descripción que hace La Cuarta del juramento de Lily Pérez ${ }^{9}$ como diputada designada en remplazo de un diputado de su bancada que había fallecido mientras ejercía su cargo:

Lily Volvió a la Cámara con percha blanca y radiante. La escalinata del Congreso se transformó en una pasarela que recibió a Lily Pérez... Si fuera una modelo farandulera habríamos dicho que se veía terriblemente rica, pero en su calidad de honorable destacamos su distinción, elegancia al vestir y buena letra (La Cuarta, 3 de enero de 2008, p.10).

Mediante el uso del humor el periódico elabora una contraposición. Pérez es identificada coloquialmente como una mujer "rica", es decir, guapa. Por ende, Pérez es identificada como una mujer del gusto masculino, idea que puede ser profundizada con el siguiente extracto: "Lily Pérez mató durante el discurso presidencial con un escotado traje negro y de medias caladas. "Todos quieren sentarse al lado mío", decía exultante" (LUN, 22 de mayo de 2009, p.6).

El extracto, se centra en detallar el atuendo "matador" de Pérez, implicando que resaltaría sus atributos corporales, usando sus propias palabras para señalar que llama la atención de los hombres haciendo que busquen estar cerca de ella. Si

${ }^{9}$ Militante de RN, candidata a senadora en las elecciones parlamentarias de 2009. 
en el caso de Rincón son sus hermosas piernas las que son un elemento indisociable de su figura, en el de Pérez es la idea de una belleza física en general la que es constantemente destacada para presentarla.

Yendo más allá del vestuario, se torna interesante indagar en los significados que se le da al hecho de ser bella, sexy, guapa o "rica", por utilizar algunos de los adjetivos con los que se las denomina, para la representación de la figura de las mujeres en política. Un primer caso se encuentra en LUN.

Refiriéndose a una encuesta vía internet que calificó a la ministra Romy Schmidt ${ }^{10}$, señala "Romy la gente te encuentra "rica"... de cabello rubio y ojos claros es la más guapa de todas. Su etiqueta dominante dice "rica"” (LUN, 14 de noviembre de 2008, p.12). LUN desarrolla una descripción visual de la imagen de la ministra en el que destaca sus ojos claros y cabellera rubia, parte integrante de los cánones estéticos de belleza femenina, que son la explicación del porqué es la más rica de todas. El periódico vuelve a resaltar lo mismo dos días después en la presentación que hacen de ella para una entrevista que le hicieron sobre el tema:

No pertenece al staff de Yingo ni ha lucido su belleza en la pasarela. Pero lo primero que se les vino a los cibernavegantes

${ }^{10}$ Militante del PPD, ministra de Bienes Nacionales durante el gobierno de Bachelet. 
al ver sus ojos azules, cabello rubio y generosa sonrisa... fue la siguiente apreciación estética: "Rica". Es la ministra de Bienes Ncionales Romy Schmidt, que ha pasado piola en el gabinete de Michelle Bachelet, pero no en la percepción inmediata de los ciudadanos ante la imagen de un político. Allí se supo que Schmidt mueve más de una hormona en los varones (LUN, 16 de noviembre de 2008, p.11).

La nota viene a señalar que su belleza es tal que logra sobreponerse a estas figuras al llamar fuertemente la atención masculina hacia ella. La imagen de Schmidt generaría un impacto que la transformaría en objeto de anhelo, pues es capaz de aludir los instintos sexuales de los hombres. Asimismo, se la puntualiza tan 'rica' como una modelo, desafiando a su vez lo que el periódico define como la imagen tradicional de un político, produciéndola como un objeto de deseo.

$\mathrm{Al}$ revisar las notas que se referían a las candidatas a puestos de representación política para las elecciones municipales y legislativas de 2008 y 2009, respectivamente, la gran mayoría utilizaba las palabras 'bella', 'guapa', 'rica', entre otras de ese estilo, como una forma de presentarlas. Esto observar con la figura de la candidata a diputada Andrea Molina ${ }^{11}$, en la imagen a continuación:

${ }^{11}$ Candidata a diputada independiente en las elecciones parlamentarias de 2009, apoyada la UDI. 
Imagen $n^{\circ} 2$

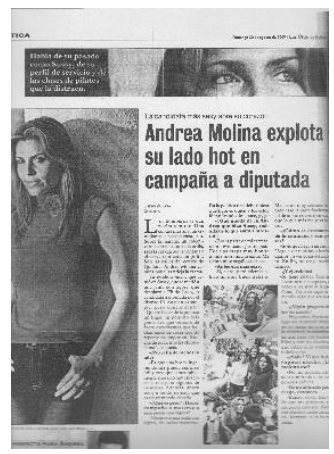

LUN, 30 de agosto de 2009, p. 10.

La imagen fotográfica de Molina ocupa la mitad del espacio asignado para la nota:

La candidata sexy abre su corazón. Los bomberos se dan vuelta a mirar. Una cuadra más allá, un estudiante se hace el chistosito. Sobre la marcha, un colectivero acerca su auto a la orilla, saca la cabeza por la ventana y observa con cara de pillín. Son las calles del centro de Quillota. Andrea Molina camina por ellas y deja la crema (LUN, 30 de agosto de 2009, p.10).

La nota destaca las reacciones que la sensualidad inherente de Molina provocaría, construyendo un escenario en el que ella se moviliza. La mera presencia de la entonces candidata atrae. Se destaca un punto que es el centro de este apartado: el ser sexy, en este caso, es una cualidad que no puede ser disociada 
de la figura de la candidata, su imagen es producida y definida a través de ella.

En el caso de los hombres que ejercen o aspiran a ejercer cargos de representación en el nivel ejecutivo y legislativo de la política, si bien existe una focalización en el cuerpo otro elemento que define el atractivo sexual son cualidades que son asociadas a la personalidad. Esto se puede apreciar en el caso de uno de los principales ministros del gabinete de Bachelet, Andrés Velasco ${ }^{12}$. La imagen $n^{\circ} 3$, que se muestra a continuación, corresponde a una portada de LUN en la que aparece en el centro la fotografía y la pregunta “ ¿Es realmente mino $^{13}$ el ministro Velasco?” (LUN, 25 de mayo de 2009, p.1):

Imagen $n^{\circ} 3$

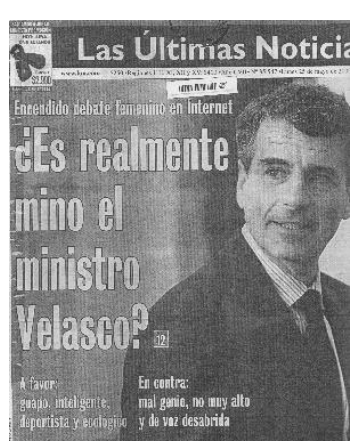

Lun, 25 de mayo de 2009, p. 1.

La portada se refiere a una discusión de usuarias de las redes sociales de internet sobre si el ministro sería "mino" o no,

\footnotetext{
${ }^{12}$ Ministro de Hacienda durante el gobierno de Bachelet.

${ }^{13}$ Modismo de tipo coloquial, es sinónimo de atractivo. En este caso se estarían preguntado si Velasco sería atractivo para las mujeres.
} 
argumentando que a su favor tendría el hecho de ser "guapo, inteligente, deportista y ecológico" (p.12), y en contra el hecho de ser "mal genio, no muy alto y de voz desabrida" (p.12.). La nota al interior del periódico presenta en extenso los argumentos en contra y a favor en base a citas de cibernautas y mujeres ligadas a la farándula chilena. El debate se resumiría en que "sus admiradoras lo encuentran guapísimo, inteligente y protector. Sus detractoras, chico y pesado" (p.12). El artículo genera un cuestionamiento a la imagen del ministro que da cuenta de los atributos que debe tener una autoridad masculina para ser considerada como un verdadero "mino", siendo alto, de voz potente y guapo. Pero no solo ser "mino" se refiere a su presencia física: debe tener otras cualidades como el ser inteligente, atlético, protector, simpático. Este cuestionamiento e introspección no solo hace una referencia sobre su figura, sino que deviene en una producción sobre ella misma: es un cuerpo sexuado sobre el cual se hace un llamado al lector para ejercer una opinión sobre él. Asimismo, se encuentra una reflexión sobre los atributos que debería tener un liderazgo masculino para ser considerado positivo dentro del imaginario: ser alto, de potente voz e inteligente podrían ser cualidades que forman parte de la construcción de un ideal, que en este caso está siendo debatido en la figura de Velasco.

Otra cualidad que forma parte de la representación de la figura de hombres en política es la galantería, como se puede 
observar en una nota referente al candidato a alcalde, Álvaro García $^{14}$. Mostrándolo sonriente, le llaman Álvaro García 2.0 en referencia a su renovación, pues de haber sido un reconocido ministro vuelve al ámbito político como aspirante a un sillón edilicio. Pero su renovación no solo tiene que ver con eso, sino con que ahora se le reconoce como un galán:

“... con años de yoga y meditación encima, el hombre de 54 años y elegido el más elegante de los candidatos a alcalde por el diario "El Mercurio", recolecta más suspiros que insultos en plena etapa puerta a puerta. Sale a trotar y anda en bicicleta “(LUN, 17 de agosto de 2008, p.13).

La galantería se asocia directamente a la elegancia. El atlético candidato, a diferencia de un político que en "un puerta a puerta" podría generar un sentimiento de rechazo, produce un anhelo hacia su figura política. Como se mencionó, la galantería de García es un símbolo de su renovación que produce un fuerte sentimiento de atracción hacia él. Así, el ser galante, en este caso, vendría asociado a la idea de novedad que traería el candidato, y representaría un tipo de liderazgo masculino positivo, como el que se discutió referente a la figura del ministro Velasco. La galantería es significada por el grado de atracción que ellos producirían para las mujeres en general, siendo así un elemento central de las modalidades de

${ }^{14}$ Militante del PPD, candidato a alcalde por la comuna de Cerro Navia en las elecciones municipales de 2008. 
erotización. El ser un galán, un verdadero “mino", es determinante para que se los produzca como sujetos de anhelo sexual por parte de las mujeres.

La afirmación realizada se despliega aún mejor en el análisis de una nota aparecida en La Cuarta, que trata de la partida de integrantes del gabinete de Bachelet. Bajo el encabezado "El guapo, el bueno y el feo abandonaron barco de La Jefa" (La Cuarta, 11 de diciembre de 2008, p. 10), se refiere a la salida del subsecretario Felipe Harboe ${ }^{15}$ (el guapo), el ministro Osvaldo Andrade ${ }^{16}$ (el bueno) y el subsecretario Arturo Barrios $^{17}$ (el feo). El encabezado hace referencia al título de un conocido film western, "El bueno, el malo y el feo", para hacer una comparación entre los tres, como puede observarse en la imagen $n^{\circ} 4$ :

Imagen $n^{\circ} 4$

La Cuarta, 11 de diciembre de 2008, p. 10

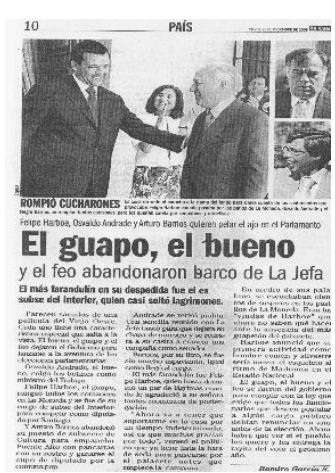

${ }^{15}$ Militante del PPD, subsecretario del Ministerio del Interior durante el gobierno de Bachelet y candidato a diputado en las elecciones parlamentarias de 2009.

${ }^{16}$ Militante del PS, subsecretario del Ministerio de Cultura durante el gobierno de Bachelet y candidato a diputado en las elecciones parlamentarias de 2009.

${ }^{17}$ Militante del PS, ministro del Trabajo y Previsión Social durante el gobierno de Bachelet y candidato a diputado en las elecciones parlamentarias de 2009. 
Harboe, cuya fotografía ocupa un espacio mayor que la de Andrade y Barrios, es el guapo debido a sus características físicas, que se contrarresta con Barrios, que destacaría por su falta de atractivo. Sin hacer mención a sus atributos físicos, se destacaría a Andrade por su eficiente gestión en el gabinete ministerial. Todos los aludidos tienen en común el haber renunciado a sus puestos en el ejecutivo con el objetivo de presentarse como candidatos a diputados para las elecciones parlamentarias de 2009. Harboe y Barrios son presentados en una relación basada en su atractivo físico, creándose una comparación. Harboe era un sujeto apreciado por las mujeres por su atractivo, mientras Barrios, por oposición, no. Esto se puede ver con la descripción que detalla que la partida del subsecretario Harboe habría sido un duro golpe para las mujeres ya que no podrían contemplarlo más:

... Felipe Harboe, el guapo, rompió todos los corazones en La Moneda y se fue de su cargo de subse del Interior para competir como diputado en Santiago... En medio de sus palabras, se escuchan cientos de suspiros en los pasillos de La Moneda. Eran las “viudas de Harboe”, que ahora no saben qué hacer ante la ausencia del más guapetón del gabinete (La Cuarta, 11 de diciembre de 2008, p. 10).

La partida de Harboe habría dejado un vacío para las mujeres que la salida de Barrios no dejó. Surge entonces una nueva 
pregunta, ¿dentro de la producción del imaginario de la esfera política institucional se debe tener una figura política sobre la que el sexo opuesto centre sus anhelos amorosos y sexuales?

Con el ejemplo de la nota referente al ministro Velasco se había explicitado la idea del cuestionamiento al atractivo de las figuras políticas masculinas. Pero ello adquiere mayor fuerza cuando se demuestra, en tono burlón, que la figura en cuestión tiene atributos poco agraciados, como lo es el sobrepeso, por ejemplo. Una nota referente a la imagen del ex ministro y potencial candidato presidencial para las elecciones de 2009, José Miguel Insulza ${ }^{18}$, es ilustrativo de ello, bajo el encabezado "A Insulza lo columpiaron por gordo, igual se zampó tortilla con chicharrón" (LUN, 4 de octubre de 2008, p. 12). La nota detalla una visita en terreno realizada por él en apoyo a la campaña de un candidato a alcalde perteneciente a la Concertación.

... prefiere relajarse con los lugareños. Se acerca a un grupo de vecinas de la tercera edad que hacen gimnasia al aire libre. Le cuentan su diario vivir, y una le habla de lo saludable que es hacer ejercicios: "Me relajo, me olvido del estrés, si hasta sirve para bajar la guata". Todos miran la esférica barriga de Insulza y estallan en risas. "Yo voy a un gimnasio todas las semanas. Años atrás, un médico me recetó caminar 3

${ }^{18}$ Militante del PS, en el período de análisis se desempeñaba como Secretario General de la Organización de Estados Americanos. 
kilómetros diarios. Pregúntele usted si lo hago o no", confiesa un empeñoso Insulza por bajar los evidentes kilos que le sobran.

No se hace la pregunta de si Insulza es o no una figura masculina atractiva. Se parte de la premisa de que no lo es e incluso se le interpela por ello. La gordura es la antítesis de las cualidades físicas que hacen que a alguien se le pueda definir como "mino". Así, Insulza resalta como una figura política masculina carente de atractivo físico. Y que, a diferencia de la figura del candidato García, no pretende renovarse al buscar mejorar su imagen corporal.

Una de las distinciones principales en la representación de la figura de mujeres y hombres que ejercen o aspiran a cargos de responsabilidad política en el nivel ejecutivo y legislativo es el enfoque en el vestuario como instrumento para resaltar los atributos físicos. En el caso de las mujeres, como se pudo observar con las menciones a la candidata a senadora Rincón y sus medias caladas o a la diputada Pérez y su traje blanco; el vestuario y como éste demarca las formas de sus cuerpos son indisociables del imaginario que se produce sobre sus figuras. En el caso de los hombres, la descripción del vestuario no es un elemento importante, casi no se menciona cuando se refieren a sus figuras. Eso no significa, como se vio, que no haya una descripción a los atributos físicos que detentan. Existe un cuestionamiento permanente a sus figuras, si son 
guapos o no, o sobre las cualidades físicas que poseen para atraer las miradas y los suspiros del público femenino. En este punto hay una otra distinción importante entre mujeres y hombres. Sobre las primeras el atractivo radica en el cuerpo. Se está ante la construcción de un imaginario sobre el cuerpo femenino asociado a los patrones estéticos imperantes de la belleza femenina.

Cuerpo firme, piernas largas, rostro angelical, cabellos rubios y ojos azules son atributos constantemente destacados en los casos analizados. Atributos que son propios de las modelos hacen que los cuerpos de las mujeres en política se destaquen llamando la atención hacia ellos, transformándolas en sujetos de contemplación y deseo sexual. En los hombres en política el atractivo se mide también por las formas del cuerpo. Sin embargo, no hay una producción de un imaginario sobre el cuerpo como se puede apreciar en el caso de las figuras femeninas en política. En su caso les están asociados otros factores que no tienen gran relevancia para medir la belleza de una mujer, pero que se tornan de gran importancia en ellos. La inteligencia, el atletismo, la capacidad de protección, entre otros, serían las cualidades necesarias para determinar si se es atractivo, un sujeto de anhelo y deseo sexual.

La seducción en la representación de la figura de mujeres y hombres en política

La vestimenta, en la representación de la figura de mujeres en política, no solo es un elemento que es utilizado para definir 
el atractivo sexual, sino que también es significada como un arma de seducción porque resalta las partes de mayor atractivo físico, describiendo las formas y las particularidades del cuerpo femenino. Sin embargo, ya no se puede referir simplemente a la idea de cuerpos femeninos que son resaltados en la representación de la esfera política nacional, sino a cuerpos femeninos seductores que actúan directamente en ella, que producen un efecto.

Describiendo el escenario de una votación al interior de la Cámara de Diputados, LUN destaca el efecto que las parlamentarias provocaron para la audiencia masculina en la tribuna:

Para votar en la Cámara los parlamentarios deben ponerse de pie, caminar hasta una mesita y dejar su papelito con las preferencias. Con las tribunas repletas de gente, eso se presta para que empiecen las tallas y los silbidos. Las beneficiadas con la aprobación del público fueron María Angélica Cristi ${ }^{19}$, Marcela Cubillos ${ }^{20}$, que sacó unos silbidos picarones y Carolina Tohá ${ }^{21}$, que lucía un ajustado traje que generó toda suerte de comentarios. Sin embargo, la más vitoreada fue

${ }^{19}$ Militante UDI, candidata a reelección como diputada en las elecciones parlamentarias de 2009.

${ }^{20}$ Militante UDI, diputada durante 2002 y 2010.

${ }^{21}$ Militante PPD, diputada durante 2002 y 2008, para después asumir como ministra en el gobierno de Bachelet. 
Claudia Nogueira ${ }^{22}$, que hasta arrancó sonoros y poco honorables besos desde las tribunas. (LUN, 14 de marzo de 2008, p. 19.).

Como se puede denotar, la nota hace una distinción entre los tipos de reacciones que provocan cada una de las diputadas, dividiendo entre silbidos, comentarios sobre sus figuras y besos. Las mujeres políticas mencionadas son retratadas no buscando adrede la atención y los halagos de los hombres que están en la tribuna del parlamento. Es su mera presencia la que incitaría la reacción fervorizada o "ardiente", una sensualidad que emana de sus cuerpos y que no pueden ocultar, a excepción de una de ellas que busca hacerse notar. Se entrevé que solamente Tohá se vistió de manera estimulante con un traje ajustado, buscando atraer para sí la atención. Pero pese a ello no es la que más resaltó, sino que fue Nogueira, la que al terminar la nota es señalada como la más atractiva para el público masculino, pues fue la más celebrada y piropeada. $\mathrm{Su}$ presencia femenina seduce, pero no busca para sí un beneficio por ello. Es un cuerpo femenino que actúa mediante una sensualidad que le es inherente, siendo un componente central que se hace de su imagen.

Un recuadro basado en una fotografía, como se puede apreciar en la imagen $\mathrm{n}^{\circ} 5$ a continuación, muestra a la presidenta

${ }^{22}$ Militante UDI, candidata a reelección como diputada en las elecciones parlamentarias de 2009. 
Bachelet sonriente, y aparentemente guiñando, hacia un militar de alto rango durante el desfile de la parada militar:

Imagen $n^{\circ} 5$

LUN, 20 de septiembre de 2009, p.3

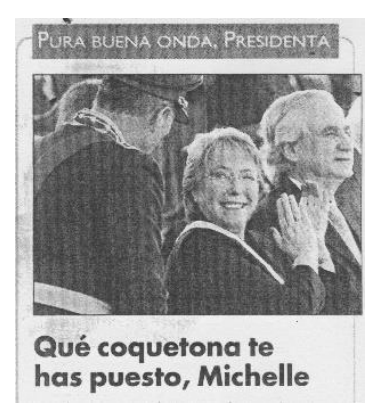

Debajo de la fotografía se anota:

Qué coquetona te has puesto, Michelle. Hay rigidez marcial y caras adustas prometiendo defender al país. Se ven fusiles y aviones prestos al combate. Pero en definitiva la Parada Militar es hecha por seres de carne y hueso, como la misma Presidenta Michelle Bachelet. Ella, generosa en sonrisas y hasta en tallas espontáneas, recordó una vez más que no todo es protocolo de Estado. Una risita no le hace mal a nadie, en especial cuando es tan expresiva que hasta se guiñan los ojos. Y cuidado los mal pensados, que nadie está insinuando nada. (LUN, 20 de septiembre de 2009, p. 3).

La imagen de Bachelet es presentada como la de una política diferente debido a su buen humor e informalidad incluso en los eventos más tradicionales. Pero ella no solo busca distinguirse por eso, sino que además hace gala de una 
coquetería identificada como propiamente femenina.

Bachelet es representada buscando diferenciarse y entretener mediante el uso de ésta. La seducción en la figura de Bachelet tendría el propósito de buscar una reacción por parte de los hombres.

Habría una búsqueda por seducir, que se puede apreciar en el caso de Daniela Donoso ${ }^{23}$ y el uso que hizo de un baby doll ${ }^{24}$ para inaugurar su campaña política, llegando a ser reconocida como la candidata del baby doll, apareciendo en el centro de una portada:

Imagen $n^{\circ} 6$

LUN, 26 de septiembre de 2008, p.1.

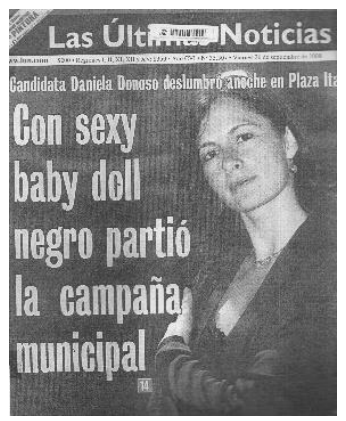

Si bien se anuncia que Donoso usó un sexy baby doll la fotografía central, correspondiente a la imagen, muestra a la "sexy" candidata usando una chaqueta sobre la prenda, cubriendo su cuerpo. La nota al interior del periódico relata la

${ }^{23}$ Militante DC, fue candidata a alcalde en las elecciones municipales de 2008 por la comuna de Providencia.

${ }^{24}$ Prenda nocturna corta para mujeres, generalmente de encaje de seda, es usualmente utilizada como vestimenta de contenido erótico. 
historia de cómo llegó a usar el baby doll. Candidatos y candidatas por la Concertación para inaugurar oficialmente la campaña municipal hicieron un acto en Plaza Italia de madrugada en la que se presentaron en pijamas:

Se trata de una decena de candidatas (y algunos candidatos también) a alcaldes y concejales de la Concertación de la Región Metropolitana, quienes están dando el vamos oficial a la campaña municipal 2008, que partió a las 00:01 de hoy. Entre ellas están Francisca Zaldívar (DC) y Danae Mylnarz (PS) que van a la pelea por los sillones edilicios de Recoleta y Ñuñoa, respectivamente. Pero las miradas no van hacia ellas... La reina de la noche es la arquitecta DC Daniela Donoso (35), quien pretende quitarle la alcaldía de Providencia a Cristián Labbé. Por simpatía y belleza no se queda. Daniela viste un sexy baby doll negro en la parte superior y un pantalón al tono. Sonríe a las cámaras, desfila como chica Morandé, anima la fría velada y acaricia quiltros. Se maneja. (LUN, 26 de septiembre de 2008, p.12).

La nota apunta a que la candidata más seductora de la noche es Donoso, al comprarla con otras políticas que no lograron atraer la atención como ella. Y Donoso sabría a propósito cómo llamar la atención y destacarse por sobre las demás mujeres, no tan solo por el uso intencionado del baby doll sino también por la forma en la que desenvuelve ante las cámaras, 
representándola como una figura femenina que utiliza su poder de seducción como parte de una estrategia política.

La seducción como modalidad de erotización tiene distintos significados en el caso de las mujeres en política. Ya sea para describir la reacción que genera la presencia de un cuerpo femenino que no busca necesariamente ser contemplado, una forma de poner a su disposición a un otro, o inclusive un medio para atraer la atención hacia sí con el objetivo de lograr una mayor votación, comprendiéndola como una estrategia, una herramienta política.

En el caso de los hombres en política se hallan dos formas de representación de la seducción que se diferencian de acuerdo al público femenino a los que se dirigen. La primera es hacia mujeres atractivas con las que se relacionarían y que buscarían conquistar para sí mismos, y, la segunda, es hacia sus electoras, a las que buscarían conquistar como parte de una estrategia para lograr votos.

La faceta seductora de los políticos se traduciría en muestran constantes de picardía ${ }^{25}$ y galantería masculina. Las mujeres bellas desatarían sus instintos seductores en la búsqueda por

${ }^{25}$ Según la Real Academia Española la palabra "picardía" o "pícaro" significa que "implica cierta intención impúdica". 
poder conquistarlas, como se observa en una nota referida al entonces ministro Francisco Vidal ${ }^{26}$.

Galancete Vidal, puro amor con ex misses. Picarón ofreció ayuda... Es simpático, elocuente y de lo más entretenido para conversar, todas facetas obvias para un vocero de gobierno. Pero hasta ahora nadie se había percatado de lo picarón que es... estuvo de lo más amoroso con las ex reinas de belleza que lideran la fundación Misses por una Causa. (LUN, 24 de enero de 2008, p.18).

La picardía y la galantería son un conjunto, una respuesta que tendrían los hombres en política ante la belleza femenina. Vidal mostraría una nueva faceta suya, llena de picardía, mostrándose amoroso y atento para lograr captar la atención de las reinas de belleza para seducirlas. Su acción se debe a una intención consciente motivada por el anhelo sexual que le provocaría las mujeres bellas. De ello se puede concluir lo que ha venido siendo destacado del análisis de cada uno: la belleza femenina produce un efecto pasional que gatilla el ritual de la seducción.

La belleza femenina como motor de la seducción masculina también puede observarse en el relato de LUN acerca del encuentro entre Insulza y Vivian Fernández, esposa del

${ }^{26}$ Militante del PPD, fue ministro de la Secretaría General y de Defensa en el gobierno de Bachelet. 
entonces presidente de Panamá, Martín Torrijos. En el apartado anterior se había señalado que la imagen física de Insulza era cuestionada debido a su sobrepeso, por lo que representaría la antítesis de lo atractivo. Sin embargo, ello no es un obstáculo para que busque seducir a una mujer. Se entrevé en el encabezado de la nota que retrata el encuentro de ambos en un acto político que encabezaban, Insulza habría quedado "loco con encantos de Primera Dama panameña" (LUN, 6 de junio de 2008, p. 18). La imagen $\mathrm{n}^{\circ} 7$ muestra una serie de fotografías que los retratan en el evento. En ellas Insulza sale contemplándola, como se muestra a continuación:

Imagen $\mathrm{n}^{\circ} 7$.

LUN, 6 de junio 2008, p.18.

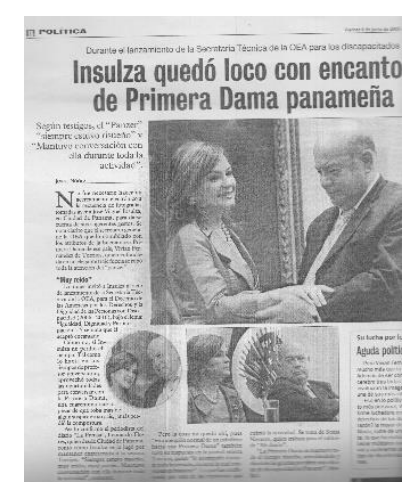

El encabezado ofrece así una interpretación para las fotografías que se muestran. Y la nota que la acompaña no hace más que rectificar el imaginario que se está construyendo del encuentro de ambos, en el que Insulza enfocaría toda su atención en ella, motivado por su belleza y elegancia: 
No fue necesario hacer un acercamiento electrónico a la secuencia de fotografías tomadas ayer a José Miguel Insulza... para darse cuenta de sus sugerentes gestos. Se nota clarito que... quedó obnubilado con los atributos de la buenamoza Primera Dama de ese país, Vivian Fernández de Torrijos, quien

enfundada en un elegante traje fucsia se robó toda la atención del "panzer". Tal como lo hacía en sus tiempos de profesor universitario, aprovechó todas las oportunidades para conversar con la Primera Dama, una cuarentona que a pesar de que se roba más de algún suspiro en su país, jamás perdió la compostura... Pero la cosa no quedó ahí pues

"esa atención normal de un caballero hacia una Primera Dama" también tuvo su respuesta en la juvenil señora Torrijos, quien lo acompaño durante toda la jornada, durante la cual conversaron bastante. (LUN, 6 de junio de 2008, p.18).

La imagen de Insulza se construye como la de un seductor a pesar de que él no cumpla con las cualidades necesarias para ser un galán. El gran atractivo de ella habría sido motivo suficiente para que él de inicio a una estrategia de conquista enfocada en otorgarle toda su atención. La primera dama, que la nota señala que se encuentra en la cuarentena, aunque a pesar de ello sigue manteniendo su belleza, no es retratada como un sujeto pasivo, sino que responde a sus avances. Ella 
deja que la atención de Insulza se centre en ella, preocupándose de atenderlo y acompañarlo durante toda la ceremonia. Se está ante un ritual cuya performance se encuentra constituida por los gestos, que LUN califica como sugerentes. Una mirada, una risa, un estrechar de manos y una conversación jovial son interpretadas bajo el signo de un comportamiento mutuo de seducción. Esta nota difiere a las anteriores pues el objeto del anhelo de la figura de un hombre en política no es una mujer ligada al ámbito del entretenimiento sino la esposa de un político de alto rango. Como se ve, no hay alusiones sexuales directas a la interacción entre ambos a diferencia de lo que ocurre en las otras notas analizadas. El extracto tiene una significación de tipo subyacente, cuya estructura y respaldo son las fotografías, en las que son representados siguiendo las pautas de un cortejo amoroso.

Una segunda forma de seducción es la que va dirigida para las electoras y que se dirige a desatar sus pasiones, sacando de ello un beneficio político. Sería un tipo de poder con el que se representan sus figuras, como puede analizarse en la siguiente nota de La Cuarta que será presentada en extenso debido a su potencial de análisis. La nota se refiere a la figura del entonces candidato a senador, Fulvio Rossi ${ }^{27}$, y su actuación durante un

27 Militante del PS, diputado y candidato a senador en las elecciones parlamentarias de 2009. 
acto de campaña de la Concertación para las elecciones parlamentarias y legislativas del año 2009:

Las hizo todas. El diputado Fulvio Rossi casi reventó el casino de Arica la noche del miércoles con su performance estilo show femenino. El actual candidato a senador por la zona se subió al escenario del recinto repleto de mujeres y se puso a cantar una canción romántica de Alejandro Lerner. Menos mal que el griterío femenino impidió que se escuchara la interpretación melódica del parlamentario que siendo amables podemos calificar de deficiente. $\mathrm{Al}$ menos por esfuerzo no se quedó porque luego les bailó a las damas presentes la tradicional "colita" que ellas agradecieron con propuestas de todo tipo. No se sabía si le estaban prometiendo votos u otra cosa. (La Cuarta, 23 de octubre de 2009, p.18).

El candidato se aprovecharía de su apariencia física para seducir a sus electoras mediante sus atributos. Primero intenta conquistarlas cantando una canción romántica a pesar de no tener una voz melódica. El efecto es tal que las mujeres gritan frenéticas llegando a un punto culmine cuando el candidato al terminar de cantar comienza a menear su trasero para ellas. La exhibición del cuerpo sería parte integral del juego de seducción que despliega en su actuación. Es ahí que las electoras gritan no sólo que votarán por él, sino que le hacen proposiciones de índole sexual, como se deja presumir por la nota. Si bien es cierto que fue el mismo candidato quien actuó 
de esta manera, cabe reflexionar las implicancias de su accionar en la representación de su figura desde una modalidad de erotización. Se hace una representación de su figura en la que hay una utilización consciente de su atractivo masculino con el objetivo de seducir para lograr un propósito concreto: ganar votos. Busca inducir a las mujeres a votar por él mediante la producción de un deseo sexual hacia su figura. La seducción, en este tipo de representación, se entiende como una herramienta de convencimiento.

La seducción es un elemento presente en la representación que se hace de mujeres y hombres en la política institucional. En ambos se establecía una diferencia sobre el propósito con el que buscaban seducir. Para las mujeres hay dos modalidades: cuando se atraían las miradas y el deseo masculino de forma inconsciente y cuando se buscaba producirlo para concretar un fin político particular. Para los hombres la seducción era siempre consciente y se diferenciaba entre seducir para lograr materializar un deseo sexual por el cuerpo de una mujer y el seducir con el objetivo de lograr, al igual que las mujeres, un fin político, que por lo general era la obtención de votos. Cabe señalar también que los hombres en política se muestran deseando a figuras que no se vinculaban directamente al mundo político institucional a diferencia de las mujeres que hasta el momento no expresaban un real deseo por el cuerpo de un ciudadano común. 
Existe una representación de la relación entre las figuras de mujeres y hombres en política que puede ser analizada bajo la óptica de las modalidades de erotización. En ellas se presenta una doble imagen que condensa el análisis que se hizo de sus figuras por separado: la de mujeres y hombres presentados como sujetos de deseo que entran en un ritual de seducción en relación con un otro que es reconocido, en este caso, como su par. La interacción entre ambos generalmente es descrita utilizando palabras como "pícara", entre otras. Un ejemplo de ello involucra la figura de la entonces diputada Pérez:

Despedida al alcalde Gustavo Hasbún ${ }^{28}$ en la parrillada Argentina. Juan A. Coloma ${ }^{29}$ y Lily Pérez lo proclaman candidato a diputado por La Florida. "Porque es grande, fuerte y puntudo", lanza la rubia RN. Vecinas presentes gritan eufóricas. "Grande, fuerte y puntudo... como la estructura de la Estación Central", aclara Lily, picarona. (LUN, 25 de noviembre de 2008, p. 9).

Se significa a Pérez como una mujer que conscientemente presenta la figura de Hasbún como la de un sujeto de gran atractivo para sus electoras, quienes responderían a ello, relacionándose con la idea de seducción como un medio para lograr un fin político. Sin embargo, en este caso, no se la

${ }^{28}$ Militante de la UDI, postuló a la reelección como alcalde de la comuna de Estación Central en las elecciones municipales de 2008.

${ }^{29}$ Militante de la UDI, candidato a senador en las elecciones parlamentarias de 2009. 
presenta entrando en un juego fluido de coquetería como si se puede observar en el siguiente extracto con un claro tono sexual. En él cuerpo de la diputada se transforma en objeto de anhelo por los demás parlamentarios:

"Lily Pérez no puede llegar a la Cámara y dejarnos a todos desconcentrados y con la boca abierta". Así decía el coqueto mensaje que el recién separado jefe de bancada PPD, Ramón Farías $^{30}$, le envió directo a su pupitre a la rubia debilidad de Renovación Nacional. Eso sí, tal como contó la parlamentaria, el ex galán de teleseries no se las llevó peladas, pues debió encararse con el diputado Osvaldo Palma ${ }^{31}$, quien le respondió que mejor mirara a sus compañeras de la Concertación "porque Lily es sólo nuestra"... Tanto las miradas de sus partidarios como las de sus detractores confirman que la aprobación de sus curvas es transversal (LUN, 6 de abril de 2009, p.14).

Sin embargo, la nota es la expresión de un imaginario en el que se reinterpreta la escena. Farías, un hombre recientemente divorciado, reacciona ante Pérez tratando de seducirla al halagar su vestimenta que resaltaría el atractivo de su figura. Sin embargo, al ser de una bancada política diferente, esto es considerado un atrevimiento, siendo defendida por un

${ }^{30}$ Militante del PPD, candidato a reelección como diputado en las elecciones parlamentarias de 2009.

${ }^{31}$ Militante RN, candidato a reelección como diputado en las elecciones parlamentarias de 2009. 
diputado de su partido, Palma, quien se encargaría de enfrentar a Farías y dejarle claro que ella les pertenece. Es su curvilíneo cuerpo el que provoca las diferentes reacciones y enfrentamientos en el parlamento. Un cuerpo bello que marca una diferencia con los demás, convirtiéndose en un objeto de anhelo en disputa. Así su figura produce un efecto seductor entre sus compañeros masculinos, que los lleva a actuar de una forma distinta con ellas.

Un segundo ejemplo de la reacción que producen en los hombres en política las mujeres en política es la figura de la diputada Ximena Vidal ${ }^{32}$ en la que se indica que ella es del gusto masculino. Después de un quiebre sentimental, la diputada viajó fuera del país, retornando con una imagen renovada a la Cámara de Diputados, que se reforzaría por un nuevo corte de cabello y un llamativo vestido. La noción de renovación, tratada tanto en el caso de mujeres como de hombres en política en los apartados anteriores, atraería las miradas de los parlamentarios hacia ella, llegando así para "matar" entre ellos:

Ximena Vidal mató con nuevo look en el Congreso... Corte de pelo y vestido parisino dejaron turulatos a sus colegas masculinos. Nadie ha dicho que los diputados son copuchentos, pero harto que la gozaron ayer comentando el

${ }^{32}$ Militante PPD, candidata a reelección como diputada en las elecciones parlamentarias de 2009. 
nuevo look de Ximena Vidal. Hubo unos, como el DC Sergio Ojeda $^{33}$, que le tomaron las manos, y otros que la piropearon y se declararon admiradores, como el UDI

Manuel Rojas ${ }^{34}$. El vestido floreado que compró en París y el nuevo corte de pelo con mechas rojizas de la diputada PPD causaron estragos en la Cámara. Además, botas de cuero negras con punta, medias al tono y una ajustada chaqueta roja. Nuevo estilo que la diputada expuso al abandonar su antiguo puesto en la tercera fila de su bancada y ubicarse en primera línea. (LUN, 9 de octubre de 2009, p. 12).

Sus compañeros diputados no quedan indiferentes ante su atractivo resaltado, teniendo reacciones como tomarle las manos en señal de bienvenida y otros de halagarla abiertamente para celebrar su nueva y aún más atractiva imagen. Como se puede apreciar, hay una descripción de su vestimenta que presenta a la diputada como un cuerpo que se distingue sobre los demás, transformándola en un sujeto de contemplación que produce un goce entre sus compañeros del Parlamento. Un cuerpo que llama la atención y sobre el cual los parlamentarios manifestarían abiertamente su deseo. Un cuerpo seductor que va reclamar un sitial de mayor preponderancia.

33 Militante de la DC, candidato a reelección como diputado en las elecciones parlamentarias de 2009.

${ }^{34}$ Militante de la UDI, candidato a reelección como diputado en las elecciones parlamentarias de 2009. 
Además de la idea del cuerpo, y más específicamente el cuerpo femenino, como un objeto de deseo en las modalidades de erotización de la relación entre mujeres y hombres en política, aparece otro tipo de significado. Éste tiene que ver con la idea del surgimiento del deseo como un anhelo de amor, como se puede ver en una nota que involucra la figura de la diputada María políticas opuestas, siendo la primera conocida por su oposición a la dictadura militar y el segundo por su apoyo público a ésta:

Saa y Moreira regalonearon de lo lindo. Amor en la cámara. Es aprobada la ley que permitirá invertir el orden de los apellidos e Iván Moreira cruza el hemiciclo para besuquear a María Antonieta Saa. Ésta no le hace nadita de asco y la sala queda plop. El parcito representa lo más polvorita de ambos sectores y ahora son como uña y mugre. "A veces no estoy de acuerdo con él, pero lo he aprendido a conocer", dice ella. Moreira la abraza. Entremedio a Juan Bustos, titular de la Cámara, lo tratan de "presidenta". Todo está trasvestido. Saa dice que "ambos estamos solteros" y se despide de Moreira con una sonrisa. Puro amor. (LUN, 11 de abril de 2008, p. 20).

La nota tiene un claro tono humorístico. El amor entre ambos habría podido concretarse al lograr la aprobación de una ley en la que estaban de acuerdo, logrando superar sus diferencias, recordando, además, que ninguno de ellos está atado a otra 
relación sentimental. Es un amor que trastoca el orden de las cosas, que es concretado por el deseo mutuo que se manifiestan y al cual se entregan libremente. El surgimiento de un deseo de amor que no tiene un fin político y que envuelve el accionar de dos figuras de edad.

Sin embargo, con la representación del 'amor' también viene la representación de los celos y las disputas por la posesión de un otro. Ello se puede observar en una nota que involucra al recién electo presidente de un partido Concertacionista, Juan Carlos Latorre ${ }^{35}$, su esposa, Rincón y la diputada Goic. El artículo se refiere a que Rincón saldrá de la mesa directiva que preside ahora su marido y será remplazada por Goic. La imagen $n^{\circ} 8$ a continuación presenta tres fotografías que quieren significar la presencia de un triángulo amoroso. En cada costado hay una fotografía de gran tamaño de cada una de las mujeres y, al centro, una imagen de Latorre, como si ambas estuvieran, de cierto modo, enfrentándose:

Imagen $n^{\circ} 8$.

LUN, 15 de diciembre de 2008, p.12.

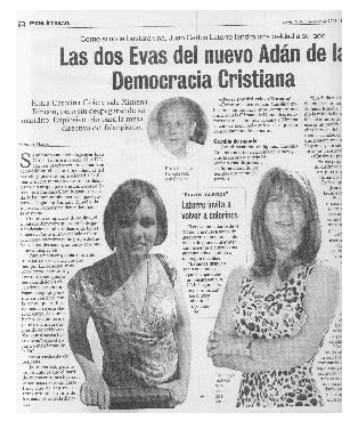

${ }^{35}$ Militante DC, candidato a reelección como diputado en las elecciones parlamentarias de 2009. 
La nota relata:

Las dos Evas del nuevo Adán de la Democracia Cristiana. Como si no bastara una, Juan Carlos Latorre tendrá otra beldad a su lado. Entra Carolina Goic y sale Ximena Rincón pero sin despegarse de su maridito... Sonriente y canchero llegó ayer... a la sede de la DC... presentó en sociedad a la flamante nueva mesa directiva de los falangistas, un grupo que tiene por rostro femenino a Carolina Goic, la guapa diputada de las "honorables piernas", que ocupará el lugar de Ximena Rincón... Con esta compañera de equipo, el diputado demostró que además de ganar elecciones sabe rodearse de bellas mujeres. Por lo mismo escogió a Carolina como miembro de su grupo de trabajo. (LUN, 15 de diciembre de 2008, p. 12).

Latorre es representado como la imagen de un hombre poderoso que logra tener permanentemente a bellas mujeres junto a él, tanto en su vida política como sentimental. Ante la belleza de su remplazante, Rincón con astucia se mantendría cerca de su marido. La senadora es representada en una suerte de contienda con Goic para no perder la atención de su marido, quien se mostraría sonriente y canchero, tal como lo señala el diario. Se habla de Latorre como el nuevo Adán, es decir el nuevo primer hombre de su partido, haciendo también alusión a la idea de triángulo amoroso al hablar de dos Evas para él. Goic es representada en cierto punto como una figura 
pasiva, pues no intenta adrede seducir a Latorre para lograr un puesto político, sin embargo, el periódico apunta a que es su belleza la que lo habría finalmente motivado a colocarla en remplazo de su esposa, activando sus celos. Si bien no se denota una estrategia de seducción propiamente tal, existe una descripción del atractivo sexual de ambas parlamentarias marcado por su belleza, colocando, como un significado subyacente, a Latorre como un conquistador. Así, las expresiones de afecto producto del surgimiento del amor, en un primer caso, y los celos, en un segundo, retrotraen en cierta medida a la acepción clásica del erotismo como amor sensual (Schatzman, 2003). Son modalidades de erotización que están marcadas tanto por la idea de un juego de seducción como de la emergencia de un fuerte sentimiento afectivo que gatilla su accionar.

En el caso de la mandataria Michelle Bachelet, hubo una representación de su figura desde la seducción como modalidad de erotización, que indicaba que su presencia desataría las pasiones de sus símiles en política, es decir, de los mandatarios extranjeros. Una nota ilustradora de ello es una que describe su encuentro con el Presidente de Brasil, Luiz Inácio Lula da Silva ${ }^{36}$, que es calificado por LUN como 'meloso'. Acorde al relato, Lula al ver a Bachelet habría tenido una reacción afectuosa:

${ }^{36}$ Presidente de Brasil durante el período 2003-2011. 
Meloso encuentro de Lula da Silva y Bachelet en Cerro Castillo. Mandatarios protagonizaron un afectuoso saludo en la cena de la Cumbre de Líderes Progresistas...Luis Inazio da Silva, conocido en todo el orbe como Lula, baja de su automóvil, y sin siquiera esperar a su traductor, camina hasta Bachelet y la rodea en sus brazos. Ambos ríen y expresan su afecto ante los ojos de la prensa. La parejita irradia buena onda. Pero el encuentro se alarga. Como buen brasileño, Lula es un hombre de afectos y no suelta de sus brazos a su par chilena (LUN, 28 de marzo 2009, p.14).

El Presidente, un hombre de afectos como recalca el periódico, no puede contener sus emociones al ver a la Presienta. Ambos se tienen afecto y lo expresan ante los demás, cruzando los límites de la formalidad del protocolo para fundirse en un abrazo. Se denota que no hay un modo explícito de aludir que Bachelet es un sujeto de deseo sexual, pues se entrevé que la jerarquía de su cargo no permite hacer este tipo de comentarios de forma directa. Sin embargo, de forma subyacente, se entiende a la figura de Bachelet como un cuerpo femenino con un gran nivel de poder político, capaz de encender las pasiones de las figuras masculinas que detentan su mismo cargo.

En la erotización de la relación entre mujeres y hombres en política en base a la seducción se puede señalar que los segundos son representados actuando de forma más activa que 
las primeras. Como lo demuestran las notas sobre Pérez y Vidal, sus cuerpos femeninos atraen no tan sólo las miradas sino el accionar de sus compañeros para conquistarlas. Las figuras en los puestos de mayor jerarquía política son representadas de manera similar, como se pudo apreciar con el retrato del encuentro entre Bachelet y Lula da Silva, actuando ambos en un ritual de cortejo. Pero no solo el deseo sexual expresado en el anhelo por poseer el cuerpo de un otro emerge dentro de las representaciones analizadas sino también el ideal del amor como un sentimiento poderoso que irrumpe en la relación entre dos figuras políticas de sexo opuesto, trayendo incluso los celos y la preocupación de perder al cuerpo amado al ser desplazados por otra figura política, como lo es el caso del triángulo amoroso entre Latorre, Rincón y Goic. Aquí la seducción no aparece como una herramienta para concretar un fin político, como fue visto en los análisis de los casos de mujeres y hombres en política por separado, sino que es la expresión del deseo sexual y el sentimiento del amor. Se puede apreciar, finalmente, la existencia de diferentes maneras de significar la relación entre mujeres y hombres en política, y que parten de la idea de la atracción producida por un otro del sexo opuesto que en la mayoría de los casos analizados aparecían como sus símiles políticos, es decir, diputada con diputado y presidenta con presidente. 


\section{Conclusiones}

En los periódicos sensacionalistas hay un mayor enfoque en las figuras políticas propiamente tales $y$ en sus confrontaciones e interacciones personales que en las ideologías políticas que detentan y propuestas que formulan. El foco en las figuras políticas desde los códigos del mundo del entretenimiento remite a una representación popularizada de la política. El interés por las medias caladas de Rincón, la pregunta sobre si el ministro Velasco puede considerarse realmente 'mino', la disputa entre parlamentarios sobre una atractiva diputada Pérez, o el abrazo meloso que se dieron la Presidenta Bachelet y el Presidente Lula; son solo algunos ejemplos que lo expresan. Todos ellos reflejan que existe una representación de la imagen de las mujeres y los hombres en política que los presentan como figuras cercanas. No son figuras políticas que se constituyen en torno a la expresión de ideas sobre la dirección que debe tomar el país, sino que son figuras personalizadas y popularizadas en el escenario de la representación política. Y dentro de los diversos modos de representación se encuentran las modalidades de erotización. Se les presenta como sujetos que se pueden mostrar deseosos por poseer el cuerpo de un otro en política, o emanando una sensualidad que atrae para sí las miradas y los suspiros sobre sus figuras.

Una pregunta a formular es el porqué de las modalidades de erotización como un medio de representación de la figura de 
mujeres y hombres en política en los periódicos sensacionalistas estudiados. Se destaca que la prensa popular sensacionalista está estructurada en códigos, expresados en un lenguaje coloquial y directo, apoyado principalmente en la interpretación de la imagen, que son identificables del mundo cotidiano del lector (Sunkel, 1985 y 2001). Las modalidades de erotización presentadas en el análisis, basadas fundamentalmente en la representación de las figuras políticas como sujetos de deseo y que desean, se producen porque son inteligibles para los lectores. La intimidad y la personalización con la que las figuras políticas son retratadas las acerca a ellos, los hace formar parte de su mundo social, siendo la erotización, con sus diversas expresiones y significaciones, una experiencia reconocible de su cotidianidad.

Las figuras políticas representadas desde las modalidades de erotización se constituyen como celebridades del espectáculo, siendo así imágenes que son consumidas por el público lector, dotándolas de diversos sentidos. Cabría preguntarse si las modalidades de erotización analizadas son síntoma de una crisis de la política representacional que se traduce en su banalización y frivolización. No puede reflexionarse en términos de tal negatividad porque son un ejemplo de cómo la irrupción de lo privado sobre lo público influye en la forma en la que se configura la representación de la imagen de las mujeres y los hombres en política. Son un reflejo de lo que 
está sucediendo en el campo político institucional, en el cual se consumen imágenes personalizadas de ellos.

La utilización de las modalidades de erotización para el análisis de la representación que realizan medios de prensa sensacionalista de la figura de mujeres y hombres que ejercen o aspiran a ejercer cargos en los niveles ejecutivo y legislativo amplia la dimensión analítica con la que los estudios sobre género y política tradicionalmente han abordado la temática de la representación mediatizada. Si bien, como se ha mencionado, la representación de la figura de las mujeres en política se hace desde la expresión del deseo sexual masculino, la representación de la figura de los hombres en política se efectúa desde la expresión de lo que sería el deseo sexual femenino. Así, aunque se retrate a éstos últimos desde la seducción como una forma de expresar sus relaciones de poder, se les presenta como sujetos de anhelo femenino mediante la imagen de la galantería. Ante los ejemplos que han sido analizados, decir que la forma en la que se representa la imagen de las mujeres en política es reflejo de la sujeción histórica de las mujeres ante los hombres es limitar las posibilidades de apertura analítica que otorga la reflexión desde la óptica de las modalidades de erotización, como se ha señalado. Pensar en estados de dominación colocaría a las figuras políticas dentro de relaciones estáticas, en las cuales no habría posibilidad de movimiento. Desde la acción de erotizar las figuras políticas interactúan, entrando en un juego 
simbólico de seducción y deseo que tiene diversas modalidades de ser representado. En este sentido, las figuras de las mujeres en política, no son pensadas entrampadas en la sumisión, sino actuando, ejerciendo una relación poder desde su sexualidad. Se critica el hecho de que sean representadas desde ahí, pero con los hombres en política, específicamente cuando las modalidades de erotización se refieren a la concreción de un objetivo de carácter político, sucede algo parecido. Obviamente, existen importantes diferencias en las formas de representar desde la erotización las figuras de mujeres y hombres en política. La principal, como fue indicada, es el enfoque en la corporalidad de las primeras para definir su atractivo, mientras que, en los segundos, si bien el atractivo físico era parte integral, también aparecían otras cualidades (como el proteccionismo, la inteligencia, entre otras, que constituiría la galantería para definir su capacidad seductora) que en las mujeres en política no tenían gran relevancia. En estas representaciones subyacen significados y nociones tradicionales sobre la feminidad y la masculinidad que han sido ampliamente discutidas por el campo de los estudios de género. Sin embargo, es necesario preguntarse, ante un escenario marcado por un escenario representacional de la política institucional tendiente hacia la popularización y personalización, cómo las figuras de las mujeres y hombres actúan, poniendo acento no tan solo en las formas en las que se diferencian sino en las diversas modalidades en las que se asemejan. 
Referencias bibliográficas

a) Textos.

Araujo, K. (1999). El erotismo en el pensamiento de Georges Bataille visto desde el psicoanálisis. Revista de la Academia, 4, 9-19.

Araujo, K. (2010). Le cas de Michelle Bachelet: médias et représentation du féminin en politique. En V. Lootvoet (Ed.), Femmes et médias. Médias et femmes (pp.83-92). Brusela : Université des Femmes.

Achin, C., y Dorlin, E. (2008). Nicolas Sarkozy ou la masculinité mascarade du président. Raisons Politiques, 31, $19-45$.

Bataille, G. (2000). El erotismo. Barcelona: Tusquets.

Bozon, M. (2005). Sociologie de la sexualité. París: Armand Collin..

Chaney, E. (1983). Supermadre. La mujer dentro de la política en América Latina. México: FCE.

Freedman, J. (1997). Femmes politiques. Mythes et symboles. París: L’Hartmattan. 
Locey, E. (2002). The pleasures of the text. Violette Leduc and the reader of seduction. Landham: Rowmann \& Lihlefield publishers.

González, S. (2007). Pornografía y erotismo. Estudios de filosofía, 36, 225-245.

Macé, É. (2006). Les imaginaires médiatiques. Une sociologie postcritique des médias. París: Armand Collin..

Millet, K. (1995). Política Sexual. Madrid: Cátedra.

Montecino, S. (1996). Madres y huachos. Alegorías del mestizaje chileno. Santiago: Sudamericana.

Piñuel, J.L (2002). Epistemología, metodología y técnicas de análisis de contenido. Estudios de Sociolingüística, 3 (1), 142.

Puleo, A. (1992). La dialéctica de la sexualidad. Madrid: Cátedra.

Rosado, J.A. (2004). Erotismo en la obra de Juan García Ponce. Contribuciones desde Coatepec, IV (7), 11-43.

Ross, K. (2004). Woman framed: the gendered turn in mediated politics. En K. Ross y C. Byberly (Eds.), Women and 
the media. International perspectives (pp.60-80). Oxford: Blackwell.

Ruiz, J. (2003). Metodología de la Investigación Cualitativa. Bilbao: Universidad de Deusto.

Schatzman, M. (2003). Consideraciones acerca del erotismo en la investigación y en la poesía del siglo XVI. Dicensa. Cuadernos de filología hispánica, 21, 281-300.

Sreberny, A., y van Zoonen, L. Introduction. En A. Sreberny y L. van Zoonen (Eds.), Gender, politics and communication (pp.1-17). Nueva Jersey: Hampton Press.

Sunkel, G. (1985). Razón y pasión en la prensa popular. Un estudio sobre cultura popular, cultura de masas y cultura política. Santiago: ILET.

Sunkel, G. (2001). La prensa sensacionalista y los sectores populares. Bogotá: Norma.

Wahl-Jorgensen, K. (2000). Constructed masculinities in U.S Presidencial campaigns: the case of 1992. En A. Sreberny y L. van Zoonen (Eds.), Gender, politics and communication (pp.53-77). Nueva Jersey: Hampton Press. New Jersey. 
b) Material de análisis.

¿Es realmente mino el ministro Velasco? (25 de mayo de 2009). Las Últimas Noticias, p. 1.

A Insulza lo columpiaron por gordo, igual se zampó tortilla con chicharrón. (4 de octubre de 2008). Las Últimas Noticias, p.12.

Álvaro García 2.0: candidato y galán. (17 de agosto de 2008). Las Últimas Noticias, p.13.

Andrea Molina explota su lado hot en campaña a diputada. (30 de agosto de 2099). Las Últimas Noticias, p.10.

Chilenas debaten por internet qué tan "mino" es el ministro Velasco. (25 de mayo de 2009). Las Últimas Noticias, p.12. Cristina y Michelle comadrearon en Punta Arenas. (5 de diciembre de 2008). Las Últimas Noticias, p.24.

Con sexy baby doll negro partió la campaña municipal. (26 de septiembre de 2008). Las Últimas Noticias, p.1.

Despampanante Lily Pérez: "Estoy hecha un huracán”. (6 de abril de 2009). Las Últimas Noticias, p.14.

Diputadas se ganaron piropos. Tribuna ardiente. (14 de marzo de 2008). Las Últimas Noticias, p.19.

El Congreso fue una pasarela. (22 de mayo de 2009). Las Últimas Noticias, p.6.

El guapo, el bueno y el feo abandonaron barco de La Jefa. (11 de diciembre de 2008). La Cuarta, p.10.

Fulvio Rossi dejó la grande en "mujerazo" ariqueño. (23 de octubre de 2009). La Cuarta, p.18. 
Insulza quedó loco con encantos de Primera Dama panameña. (6 de junio de 2008). Las Últimas Noticias, p.18.

La matadora pinta de Ximena Rincón. (6 de abril de 2009). Las Últimas Noticias, p.12

Lily Pérez volvió a la Cámara con percha blanca y radiante. (3 de enero de 2008). La Cuarta, p.10.

Lily proclama al "puntudo" Hasbún. (25 de noviembre de 2008). Las Últimas Noticias, p.9.

Galancete Vidal, puro amor con ex misses. (24 de enero de 2008). Las Últimas Noticias, p.18.

Ministra Schmidt: "Nunca me he sentido la tremenda mina rica”. (16 de noviembre de 2008). Las Últimas Noticias, p.11. Romy, la gente te encuentra "rica". (14 de noviembre de 2008). Las Últimas Noticias, p.12.

Sexy candidata se paseó con baby doll a media noche por Plaza Italia. (26 de septiembre de 2008). Las Últimas Noticias, p.14.

Ximena Vidal mató con nuevo look en el Congreso: "Buscaré pololo en otro lado". (9 de octubre de 2009). Las Últimas Noticias, p. 12.

Saa y Moreira regalonearon de lo lindo. (11 de abril de 2008). Las Últimas Noticias, p.20.

Las dos Evas del nuevo Adán de la Democracia Cristiana. (15 de diciembre de 2008). Las Últimas Noticias, p.12. Meloso encuentro de Lula da Silva y Bachelet en Cerro Castillo. (28 de marzo de 2009). Las Últimas Noticias, p.14. 
Revista de la Academia/ISSN 0719-6318

Volumen 23/Otoño de 2017

Mariana Valenzuela

Ximena Rincón mató con medias caladas y crítico el 21 de mayo: "Faltó más audacia". (22 de mayo de 2008). Las Últimas Noticias, p.2. 